\title{
Clinical characteristics and risk factors associated with severe COVID-19: prospective analysis of 1,045 hospitalised cases in North-Eastern France, March 2020
}

Charlotte Kaeuffer ${ }^{1}$, Coralie Le Hyaric ${ }^{1,2}$, Thibaut Fabacher ${ }^{2,3}$, Joy Mootien ${ }^{4}$, Benjamin Dervieux ${ }^{5}$, Yvon Ruch ${ }^{1}$, Antonin Hugerot ${ }^{1}$ , Yves-Jean Zhu ${ }^{1}$, Valentin Pointurier ${ }^{4}$, Raphael Clere-Jeh ${ }^{6}$, Valentin Greigert ${ }^{7}$, Loic Kassegne ${ }^{8}$, Nicolas Lefebvre ${ }^{1}$, Floriane Gallais 9 , Covid Alsace Study Group ${ }^{10}$, Nicolas Meyer ${ }^{3,11}$, Yves Hansmann ${ }^{1}$, Olivier Hinschberger ${ }^{5}$, François Danion ${ }^{1}$

1. CHU de Strasbourg, Department of Infectious and Tropical Diseases; Fédération de Médecine Translationnelle de Strasbourg, Université de Strasbourg, Strasbourg, France

2. These authors contributed equally

3. Université de Strasbourg, ICube, équipe IMAGeS, UMR7357, Strasbourg, France

4. Groupe Hospitalier Régional Mulhouse Sud Alsace, Intensive Care Unit, Mulhouse, France

5. Groupe Hospitalier Régional Mulhouse Sud Alsace, Department of Internal Medicine, Mulhouse, France

6. CHU de Strasbourg, Medical Intensive Care Unit, Nouvel Hôpital Civil, Strasbourg, France

7. CHU de Strasbourg, Department of Internal Medicine, Nouvel Hôpital Civil, Strasbourg, France

8. CHU de Strasbourg, Department of Pneumology, Strasbourg

9. CHU de Strasbourg, Department of Virology, Fédération de Médecine Translationnelle, Université de Strasbourg, Strasbourg, France

10. The members of the Covid Alsace Study Group are listed at the end of the article

11. CHU de Strasbourg, Department of Public Health, GMRC, Strasbourg, France

Correspondence: François Danion (francois.danion@chru-strasbourg.fr)

Ivestigator group:

COVID Alsace Study Group: Hamid Merdji, Paul-Michel Mertes, Walid Oulehri, Charles Tacquard, Olivier Collange, Pierre-Olivier Ludes, Sophie Diemunsch, Francis Schneider, Thomas Lemmet, Anne-Sophie Damour, Martin Behr, Pierrick Le Borgne, Emmanuel Chatelus, Renaud Felten, Adrien Zecchi, Flavie Maitrepierre, Jean-

Edouard Terrade, Louis Boehn, Abrar Ahmad Zulfiqar, Aurélien Guffroy, Vincent Poindron, Sylvain Lescuyer, Elise Schmitt, Cédric Waechter, Cécile Ronde-Oustau,

Frédéric De Blay, Philippe Fraisse, Peggy Perrin, Nicolas Keller, Mary Pontvianne, Fanny De Marcillac, Philippe Deruelle, Marie-Laure Legris, Mégane Wehr, Floriane

Frédéric De Blay, Philippe Fraisse, Peggy Perrin, Nicolas Keller, Mary Pontvianne, Fanny De Marcillac, Philippe Deruelle, Marie-Laure Legris, Mégane Wehr, Floriane
Zeyons, Jean-Jacques Von Hunolstein, Pierre Leyendecker, Mickael Ohana, Aissam Labani, Clémence Risser, Thibaut Goetsch, Noémie Leclerc Du Sablon, Marion

Ehret, Frederic Vinee, Myriam Bernard, Clémence Koch, Arnaud Waegell, Léa Dormegny, Alexandra Daguet, Stéphanie Deboscker, Thierry Lavigne, Samira Fafi-

Kremer, Aurélie Velay, Morgane Solis, Marie-Josée Wendling, Héloïse Delagreverie, Ilies Benotmane, Elise Dicop, Lionel Martzolff, Pierre Oudeville

Citation style for this article:

Both L, Botgros R, Cavaleri M. Analysis of licensed over-the-counter (OTC) antibiotics in the European Union and Norway, 2012. Euro Surveill.

2015;20(34):pii=30002. DOI: http://dx.doi.org/10.2807/1560-7917.ES.2015.20.34.30002

Article submitted on 11 May 2020 / accepted on 14 Aug 2020 / published on 03 Dec 2020

Background: In March 2020, the COVID-19 outbreak was declared a pandemic by the World Health Organization. Aim: Our objective was to identify risk factors predictive of severe disease and death in France. Methods: In this prospective cohort study, we included patients $\geq 18$ years old with confirmed COVID19, hospitalised in Strasbourg and Mulhouse hospitals (France), in March 2020. We respectively compared patients who developed severe disease (admission to an intensive care unit (ICU) or death) and patients who died, to those who did not, by day 7 after hospitalisation. Results: Among 1,045 patients, 424 (41\%) had severe disease, including $335(32 \%)$ who were admitted to ICU, and $115(11 \%)$ who died. Mean age was 66 years (range: 20-100), and 612 (59\%) were men. Almost 75\% of patients with body mass index (BMI) data $(n=897)$ had a $B M I \geq 25 \mathrm{~kg} / \mathrm{m}^{2}(\mathrm{n}=661)$. Independent risk factors associated with severe disease were advanced age (odds ratio (OR): 1.1 per10-year increase; $95 \% \mathrm{Crl}$ (credible interval): 1.0-1.2), male sex (OR:2.1; 95\% Crl: 1.52.8), BMI of $25-29.9 \mathrm{~kg} / \mathrm{m}^{2}$ (OR:1.8; $95 \% \mathrm{Crl}: 1.2-2.7$ ) or $\geq 30 \quad$ (OR: 2.2; $95 \%$ Crl: 1.5-3.3), dyspnoea (OR: $2.5 ; 95 \% \mathrm{Crl}: 1.8-3.4)$ and inflammatory parameters (elevated C-reactive protein and neutrophil count, low lymphocyte count). Risk factors associated with death were advanced age (OR:2.7 per10-year increase; 95\% Crl: $2.1-3.4$ ), malesex(OR:1.7; $95 \% \mathrm{Crl}: 1.1-$ 2.7), immunosuppression (OR:3.8; 95\% Crl: 1.6-7.7), diabetes (OR:1.7;95\% Crl:1.0-2.7), chronic kidney disease (OR:2.3;95\% Crl:1.3-3.9), dyspnoea (OR: 2.1;95\% Crl: 1.2-3.4) and inflammatory parameters. Conclusions: Overweightedness, obesity, advanced age, male sex, comorbidities, dyspnoea and inflammation are risk factors for severe COVID-19 or death in hospitalised patients. Identifying these features among patients in routine clinical practice might improve COVID-19 management.

\section{Introduction}

An outbreak of pneumonia linked to a new coronavirus termed severe acute respiratory syndrome coronavirus 2 (SARS-CoV-2) was first reported in Wuhan, China, in December 2019 [1]. Coronavirus disease 2019 (COVID19), which is caused by this virus, then rapidly spread globally resulting in a pandemic. On 13 March 2020, the World Health Organization (WHO) declared Europe the new epicentre of the pandemic, as more cases and deaths were reported there at that time compared to other areas of the world [2]. Among European countries, Italy, France, Spain and the United Kingdom 
TABLE 1

Demographic characteristics and comorbidities of COVID-19 patients at admission to hospital, North-Eastern France, March 2020 ( $\mathrm{n}=1,045$ patients)

\begin{tabular}{|c|c|c|c|c|c|c|c|c|}
\hline \multirow[t]{2}{*}{ Characteristics } & \multicolumn{2}{|c|}{$\begin{array}{l}\text { All patients } \\
n=1,045\end{array}$} & \multicolumn{2}{|c|}{$\begin{array}{l}\text { Non severe disease } \\
\qquad n=621\end{array}$} & \multicolumn{2}{|c|}{$\begin{array}{l}\text { Severe disease } \\
\qquad n=424\end{array}$} & \multirow[t]{2}{*}{$\begin{array}{l}\text { Difference in } \\
\text { proportion of the } \\
\text { event }(\mathrm{Crl})\end{array}$} & \multirow[t]{2}{*}{ Pr diff $>0$} \\
\hline & Number $^{\mathrm{a}}$ & $\%^{a}$ & Numbera & $\%^{a}$ & Numbera & $\%^{a}$ & & \\
\hline Age, years, mean (SD) & \multicolumn{2}{|c|}{$66.3(16.0)$} & \multicolumn{2}{|c|}{$65.6(17.4)$} & \multicolumn{2}{|c|}{$67.3(13.4)$} & $-1.6(-3.5$ to 0.2$)$ & 0.045 \\
\hline Male sex & 612 & 58.6 & 309 & 49.8 & 303 & 71.5 & $-18.0(-23.3$ to -12.6$)$ & $<0.001$ \\
\hline \multicolumn{9}{|l|}{$\mathrm{BMI}^{\mathrm{b}}$} \\
\hline$<25 \mathrm{~kg} / \mathrm{m}^{2}$ & 236 & 26.3 & 169 & 32.4 & 67 & 17.9 & \multicolumn{2}{|c|}{ Reference } \\
\hline $25-29.9 \mathrm{~kg} / \mathrm{m}^{2}$ & 310 & 34.6 & 166 & 31.8 & 144 & 38.4 & $-13.0(-19.9$ to -6.1$)$ & $<0.001$ \\
\hline$\geq 30 \mathrm{~kg} / \mathrm{m}^{2}$ & 351 & 39.1 & 187 & 35.8 & 164 & 43.7 & $-13.4(-20.1$ to -6.6$)$ & $<0.001$ \\
\hline \multicolumn{9}{|l|}{ Comorbidity } \\
\hline Hypertension & 548 & 52.4 & 317 & 51.0 & 231 & $54 \cdot 5$ & $-2.8(-8.3$ to 2.7$)$ & 0.157 \\
\hline Diabetes & 264 & $25 \cdot 3$ & 148 & 23.8 & 116 & 27.4 & $-3.4(-9.4$ to 2.7$)$ & 0.139 \\
\hline Active smoking & 36 & 3.4 & 25 & 4.0 & 11 & 2.6 & $3.4(-5.3$ to 11.8$)$ & 0.781 \\
\hline Chronic heart failure & 121 & 11.6 & 75 & 12.1 & 46 & 10.8 & $1.9(-5.3$ to 8.9$)$ & 0.701 \\
\hline $\begin{array}{l}\text { Chronic respiratory } \\
\text { disease }^{c}\end{array}$ & 172 & 16.5 & 93 & $15 \cdot 0$ & 79 & 18.6 & $-4.2(-10.9$ to 2.4$)$ & 0.109 \\
\hline Chronic kidney disease & 117 & 11.2 & 68 & 11.0 & 49 & 11.6 & $-0.7(-7.9$ to 6.5$)$ & 0.430 \\
\hline Chronic hepatic failure & 11 & 1.1 & 8 & 1.3 & 3 & 0.7 & $1.9(-7.6$ to 11.2$)$ & 0.657 \\
\hline Immunosuppression $^{d}$ & 48 & 4.6 & 25 & 4.0 & 23 & 5.4 & $-2.4(-10.9$ to 6.0$)$ & 0.294 \\
\hline Cancere & 109 & 10.4 & 65 & 10.5 & 44 & 10.4 & $0.4(-6.9$ to 7.6$)$ & 0.540 \\
\hline $\begin{array}{l}\text { Haematological } \\
\text { malignancy }\end{array}$ & 32 & 3.1 & 12 & 1.9 & 20 & $4 \cdot 7$ & $-5 \cdot 5(-14.6$ to $3 \cdot 3)$ & 0.113 \\
\hline Pregnancy & 15 & 1.4 & 13 & 2.1 & 2 & 0.5 & $4.4(-4.9$ to 13.4$)$ & 0.825 \\
\hline \multicolumn{9}{|c|}{ Treatment in the previous month } \\
\hline NSAIDs $^{f}$ & 51 & 5.0 & 32 & 5.6 & 19 & 4.6 & $1.1(-7.2$ to 9.3$)$ & 0.610 \\
\hline ACE inhibitors & 185 & 17.7 & 107 & 17.2 & 78 & 18.4 & $-1.2(-7.7$ to 5.3$)$ & 0.361 \\
\hline AllRAs & 188 & 18.0 & 110 & 17.7 & 78 & 18.4 & $-0.6(-7.1$ to 5.7$)$ & 0.424 \\
\hline $\begin{array}{l}\text { Mean time from onset of } \\
\text { symptoms to admission } \\
\text { (SD), in days }\end{array}$ & \multicolumn{2}{|c|}{$7.2(5 \cdot 3)$} & \multicolumn{2}{|c|}{$6.9(5.4)$} & \multicolumn{2}{|c|}{$7.6(5.1)$} & $-0.7(-1.4$ to 0.0$)$ & 0.033 \\
\hline
\end{tabular}

ACE: angiotensin-converting enzyme; AIIRAs: angiotensin II receptor antagonists; BMI: body mass index; Crl: credible interval; diff.: difference; NSAIDs: non-steroidal anti-inflammatory drugs; Pr: probability; SD: standard deviation.

a Numbers and percentages are presented in the column unless specified otherwise by the row heading.

b Data available for 897 patients.

' 60 patients presented with asthma, 54 with chronic obstructive pulmonary disease, 47 with obstructive sleep apnoea and 20 with other chronic respiratory disease (some patients presented with >1 disease).

${ }^{\mathrm{d}} 22$ patients presented with solid organ transplantation, 16 with immunosuppressive drugs, two with human immunodeficiency virus and eight with other immunodeficiency.

e Active or in remission.

${ }^{\mathrm{f}}$ Data available for 1,023 patients.

Probabilities near 1 or 0 are both suggestive of an effect, respectively of a positive or negative difference, and are marked in bold.

(UK) were severely affected. On 2 August 2020, the European Centre for Disease Prevention and Control reported $17,841,669$ confirmed cases in the world with 685,281 deaths, and 1,733,550 confirmed cases in the European Union/European Economic Area (EU/EEA) and the UK, with 182,639 deaths [3]. In France, 187,919 confirmed cases, and 30,265 deaths were reported on this same date. The Alsace region in the North-East of France, harboured an important COVID-19 cluster.
The clinical spectrum of COVID-19 ranges from the absence of symptoms to life-threatening severe acute respiratory distress syndrome (ARDS) and death, making the detection and isolation of COVID-19 cases complex and facilitating the spread of the virus [4-7]. In turn, this can lead to overall increases in numbers of patients having severe disease, with the potential to overwhelm the capacity of intensive care units (ICU). To mitigate this problem, predicting which patients may be most affected by severe COVID-19 is critical. 


\section{FIGURE 1}

Proportions of patients with certain clinical symptoms at admission among patients with non-severe and severe COVID-19 by day 7, North-Eastern France, March 2020 (n=1,045 patients)

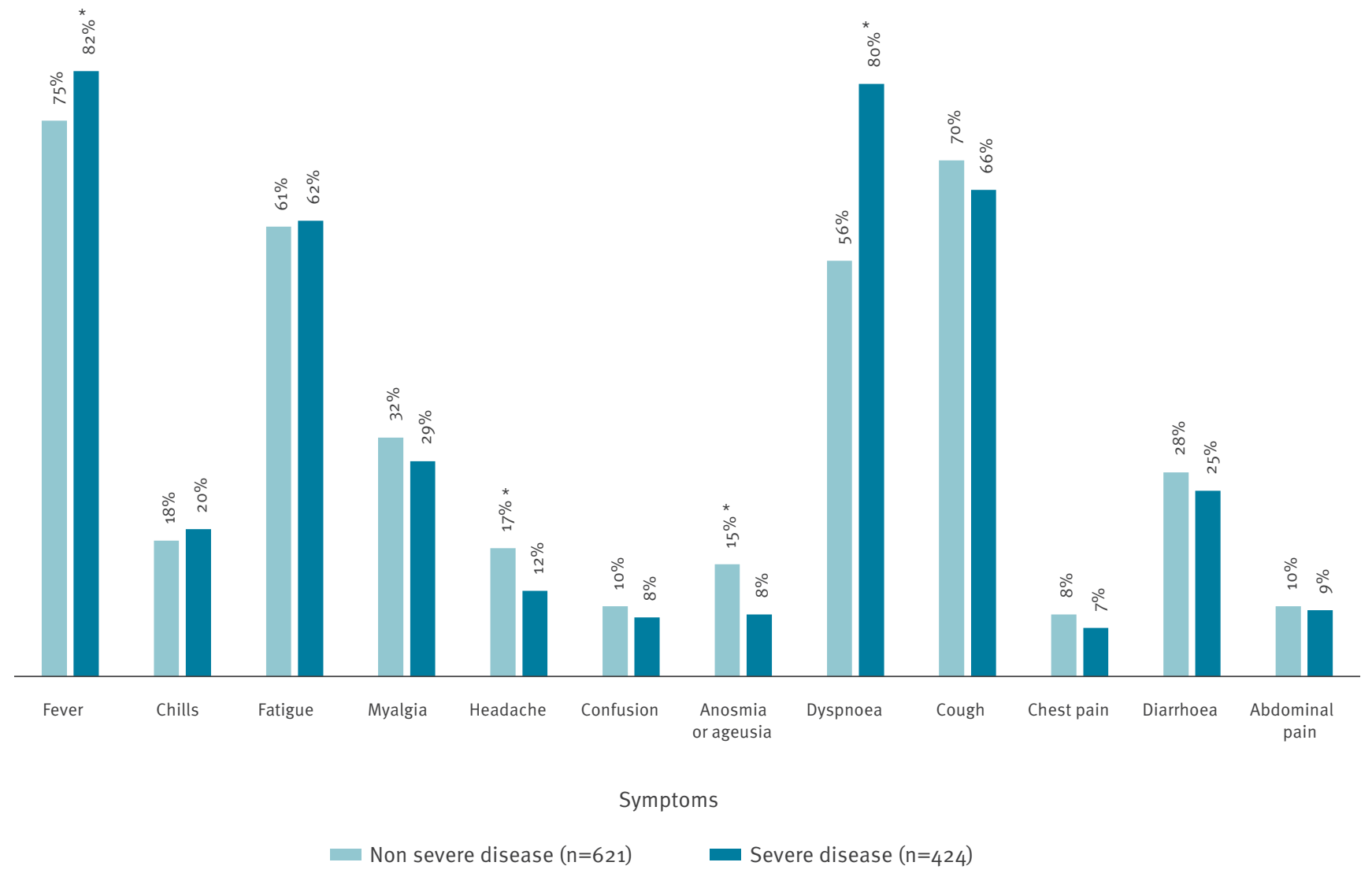

COVID-19: coronavirus disease.

* Probability (Pr) that the between-group difference was larger than o $(\operatorname{Pr}(\operatorname{diff}>0))$, suggestive of an effect.

Most primary reports on risk factors associated with poor prognoses linked to COVID-19 have come from China $[8,9]$. In this study, such factors are investigated in France and we report the clinical, biological and radiological characteristics of a large cohort of patients hospitalised for COVID-19 in two main hospitals, Strasbourg and Mulhouse, located in the Alsace region. Our objective was to highlight factors identifiable through routine clinical practice that could predict severe COVID-19 development and death during the first wave of the pandemic. We aimed to find ways to easily identify patients who should be closely monitored and may benefit from specific therapies.

\section{Methods}

\section{Study design and participants}

We conducted a non-interventional prospective study of adult COVID-19 patients who were hospitalised in two different hospitals in Alsace, France: Strasbourg University Hospital and Mulhouse Hospital. Inclusion criteria were patient $s \geq 18$ years old with a positive result for SARS-CoV-2 by PCR (thereafter referred to as COVID-19 patients) who were hospitalised in March 2020.

We compared two groups of patients: one with nonsevere disease and the other with severe disease. Severe disease was defined by composite criteria, including death or admission to ICU in the 7 days following hospitalisation [10]. We also compared patients who died within 7 days to those who were still alive. Characteristics to be assessed for the development of severe disease and death were obtained at admission.

\section{Setting}

The Strasbourg University Hospital, located in the north of the Alsace region, France, contains 2,566 beds including 97 in the ICU and serves a catchment area of approximately 1 million inhabitants. The Mulhouse Hospital, situated in the south of Alsace holds 2,500 beds, including 36 in the ICU, for a catchment area of ca 480,000 inhabitants. The ICU bed capacity was increased to 207 in Strasbourg Hospital to handle the rapid increase of COVID-19 cases and to 85 in Mulhouse Hospital, including 30 beds from the French Army (not 


\section{FIGURE 2}

Outcome of COVID-19 patients depending on the age and BMI, North-Eastern France, March 2020 ( $\mathrm{n}=1,045$ patients)

A.

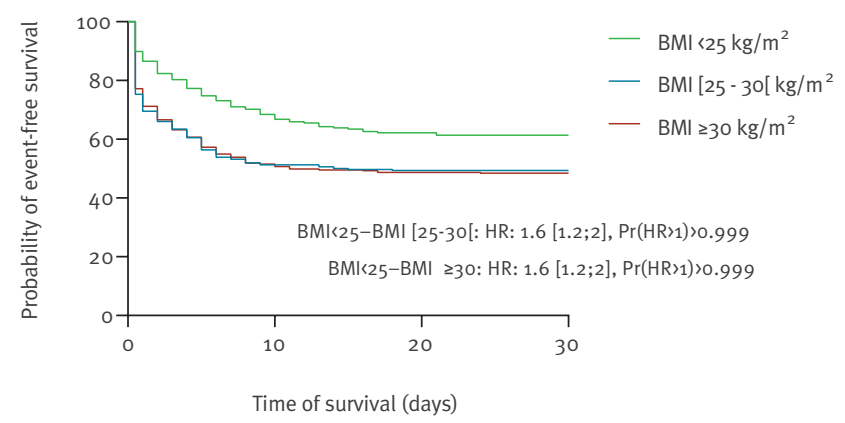

B.

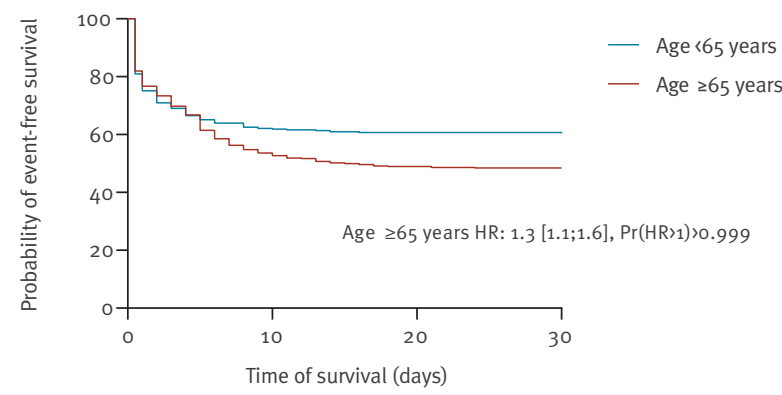

C.

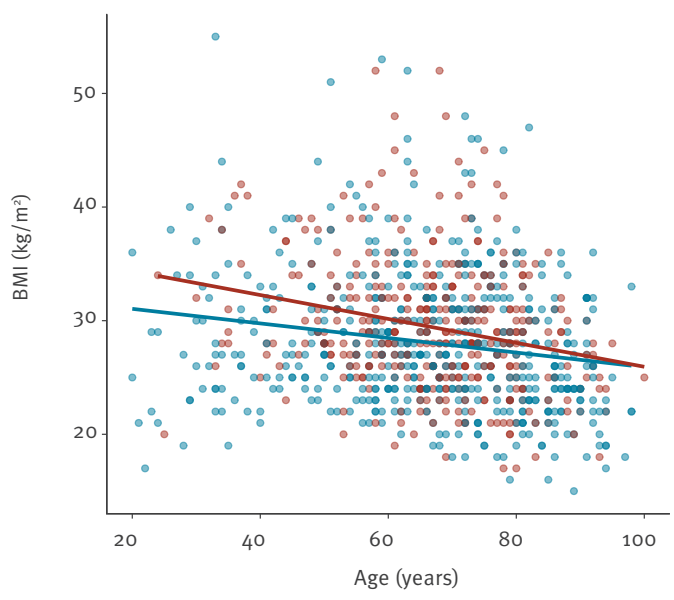

Non severe $r=-0.17[-0.26 ;-0.09]$

Severe $\mathrm{r}=-0.25[-0.34 ;-0.15]$

Severe disease $\rightarrow$ No
Death
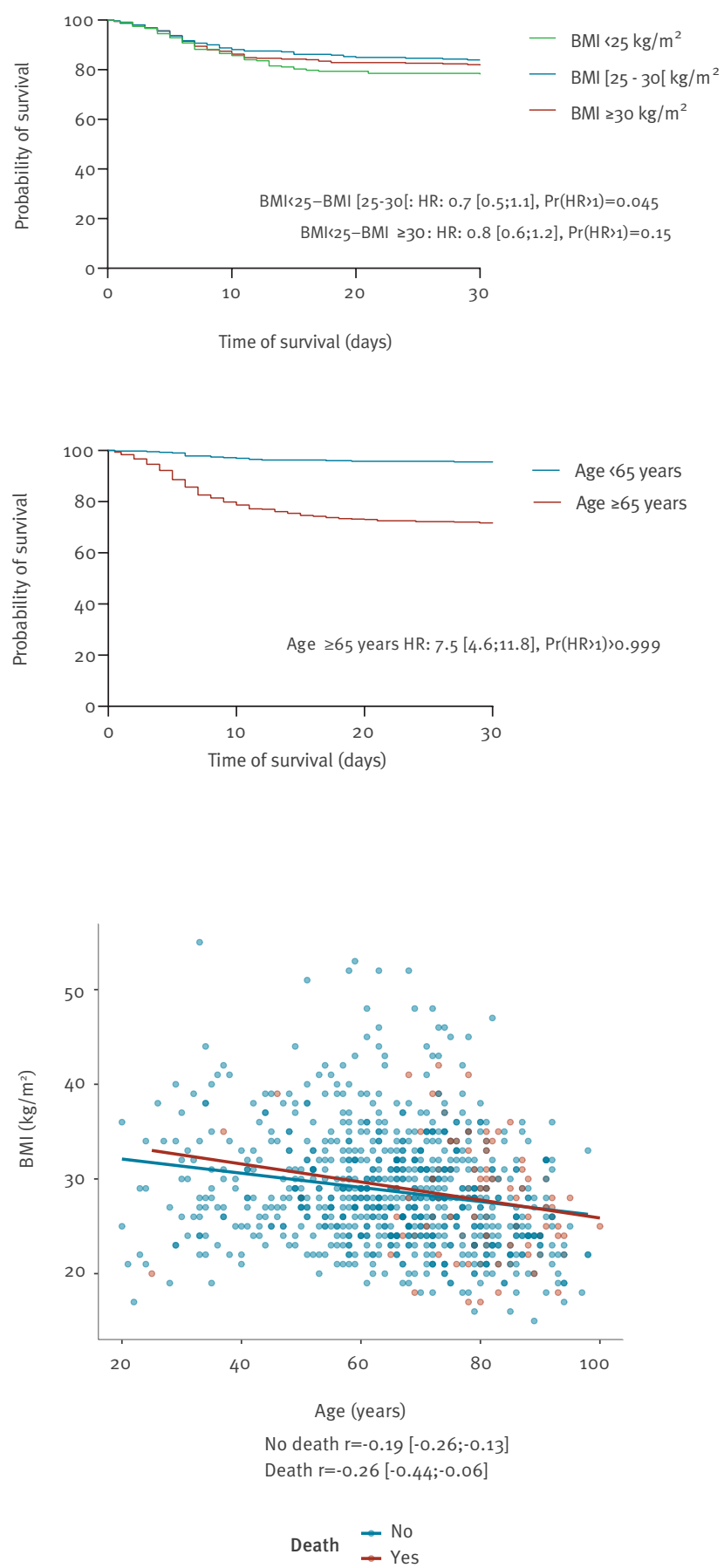

BMI: body mass index; COVID-19: coronavirus disease; HR: hazard ratio; ICU: intensive care unit; Pr: probability.

(A) Probability of event-free survival (no admission to ICU or death, left panel) and survival (no death, right panel) according to BMI.

(B) Probability of event-free survival (left panel) and survival (right panel) according to age.

(C, left panel) Correlation between age and BMI in patients with non-severe (correlation coefficient $r=-0.17)$ or severe disease $(r=-0.25)$ at day 7.

(C, right panel) Correlation between age and BMI in patients who died $(r=-0.26)$ or who were alive $(r=-0.19)$ at day 7 . 
included in this study), at the peak of the pandemic in France (end of March 2020).

\section{Data collection}

Data collected for hospitalised COVID-19 patients included epidemiological, clinical, laboratory, radiological and treatment data at day of admission and during the 7 days of follow-up. These data were collected from electronic medical records using a standardised consent report form. The seriousness of disease was assessed on the first day according to an eight-category ordinal scale [11]. The outcome (ICU and/or death) was recorded by day 7 , to identify risk factors associated with rapid worsening of the patients' condition after hospital admission. This early time point was suggested by previous studies which showed that the median time from dyspnoea to admission in the ICU was 3 to 5 days [9].

\section{Additional tests and definitions}

Laboratory testing for SARS-CoV-2 infection was centralised in Strasbourg University Hospital. Quantitative real-time reverse transcriptase PCR (qRT-PCR) tests for SARS-CoV2 nucleic acid were performed on nasopharyngeal swabs, sputum, tracheal aspiration, or bronchoalveolar lavage [12]. Primer and probe sequences used in this hospital target two regions on the RNA-dependent RNA polymerase (RdRp) gene and are specific to SARS-CoV2. Assay sensitivity is around 10 copies perreaction.

Computed tomography scanning of the chest was performed on most patients and the result was classified by radiologists as being compatible with COVID19 , uncertain, showing a non-infectious pattern or a normal pattern. Being overweight and obesity were defined according to the WHO as a body mass index $(\mathrm{BMI}) \geq 25 \mathrm{~kg} / \mathrm{m}^{2}$ and $\mathrm{BMI} \geq 30 \mathrm{~kg} / \mathrm{m}^{2}$, respectively [13].

\section{Statistical analysis}

The data were analysed with Bayesian methods. The data were described as frequency (\%) for categorical variables and mean (range or standard deviation (SD)) for continuous variables. Between-group differences and odds ratios (OR) are given with their $95 \%$ credible intervals $(\mathrm{Crl})$. The primary outcome was analysed using logistic regression, with priors defined before the study and based on mild assumptions derived from expert knowledge and available literature (priors for beta coefficients: normal distribution $(0,2.3))$. A random centre effect was added and tested. We computed the probability $(\mathrm{Pr})$ that the between-group difference is larger than $0(\operatorname{Pr}($ diff $>0))$ and, in the multivariate analysis, the probability that the OR is larger than 1 . In the multivariate analyses, missing data were imputed using prior distributions derived from observed data.

All demographic, clinical and biological variables with a $\operatorname{Pr}($ diff $>0)<0.025$ or a $\operatorname{Pr}($ diff $>0)>0.975$ in the univariate analysis or of clinical relevance were included in the multivariate model. Data with more than $15 \%$ missing data points were not included in the multivariate analysis.

For the survival analysis, a Bayesian version of Cox model was used. We remind that Bayesian methods do not use pvalues and that the computed probabilities must not be confused with pvalues. Probabilities near 1 or 0 are both suggestive of an effect, respectively of a positive or negative difference, or of an OR larger or smaller than 1 . All computations were done with $R$ 3.3.1 and JAGS software with all required additional packages.

\section{Ethical statement}

The study was approved by the Ethics Committee of the University Hospital of Strasbourg ( $\left.{ }^{\circ} \mathrm{CE}-2020-51\right)$. The patients who expressed opposition to participate were not included. Written consent was waived in the context of an emerging infection. The study has been registered in ClinicalTrials.gov under the number NCTo4362345.

\section{Results}

Characteristics of patients at admission

A total of 1,045 hospitalised COVID-19 patients were included in this study: 192 were from Mulhouse Hospital, and 853 were from Strasbourg University Hospital. The mean age was 66 years (range: 20-100), and $612(59 \%)$ were men (Table 1$)$. The mean ages in women and men were 68 (range:20-100) and 65 (range: $21-98)$ years $(\operatorname{Pr}(\operatorname{diff}>0)=0.997)$, respectively.

The mean BMI was $28.6 \mathrm{~kg} / \mathrm{m}^{2}$ (range: $15-55$ ); 310 (34.6\%) patients had a BMI of $25-30 \mathrm{~kg} / \mathrm{m}^{2}$ and 351 (39.1\%) patients had $\mathrm{BMI} \geq 30 \mathrm{~kg} / \mathrm{m}^{2}$. Patients with a $\mathrm{BMI} \geq 25 \mathrm{~kg} / \mathrm{m}^{2}$ were younger (65years; range: $21-98$ ) than those with a BMl $25 \mathrm{~kg} / \mathrm{m}^{2}$ (71 years; range: 20-100; $\operatorname{Pr}($ diff $>0)>0.999)$. Demographic, clinical and biological findings by BMI category are provided in Supplementary Table 1.

In our cohort, $613(58.7 \%)$ patients had at least one comorbidity (Table 1). The most predominant comorbidity was hypertension $(548,52.4 \%)$, followed by diabetes $(264,25.3 \%)$ and chronic respiratory disease $(172,16.5 \%)$.

The most common symptoms at admission to the hospital were fever $\left(\geq 38^{\circ} \mathrm{C} ; \mathrm{n}=816\right.$ patients, $\left.78.1 \%\right)$, cough (715, 68.4\%), and dyspnoea (691, 66.1\%) (Figure 1). Extra-pulmonary symptoms, such as diarrhoea (279, $26.7 \%)$, headache $(157,15.0 \%)$ and anosmia/ageusia (94 of 757 with available data, 12.4\%) were also recorded. Mean duration of symptoms from onset to admission was 7.2 days (SD:5.3).

On the first day of admission, 271 (25.9\%) patients had an eight-category ordinal scale of 4 (hospitalised, not requiring oxygen), $588(56.3 \%)$ had a score of 5 (hospitalised, requiring oxygen), 181 (17.3\%) had a score of 
TABLE 2

Multivariate analysis of factors associated with severe disease and death

\begin{tabular}{|c|c|c|c|c|c|c|}
\hline \multirow{2}{*}{ Characteristic } & \multicolumn{3}{|c|}{ Severe disease (ICU + death) } & \multicolumn{3}{|c|}{ Death } \\
\hline & OR & $95 \% \mathrm{Crl}$ & $\operatorname{Pr} O R>1$ & OR & $95 \% \mathrm{Crl}$ & $\operatorname{Pr} O R>1$ \\
\hline Age, per10-year increase & 1.1 & $1.0^{\mathrm{a}-1.2}$ & $>0.999$ & 2.7 & $2.1-3.5$ & $>0.999$ \\
\hline Male sex ${ }^{b}$ & 2.1 & $1.5-2.8$ & $>0.999$ & 1.7 & $1.1-2.7$ & 0.986 \\
\hline \multicolumn{7}{|l|}{$\mathrm{BMI}, \mathrm{kg} / \mathrm{m}^{2}$} \\
\hline$<25$ & \multicolumn{3}{|c|}{ Reference } & \multicolumn{3}{|c|}{ Reference } \\
\hline $25-29.9$ & 1.8 & $1.2-2.7$ & 0.999 & 0.9 & $0.5-1.6$ & 0.315 \\
\hline$\geq 30$ & 2.2 & $1.5-3.3$ & $>0.999$ & 1.4 & $0.7-2.5$ & 0.831 \\
\hline \multicolumn{7}{|l|}{ Comorbidity ${ }^{c}$} \\
\hline Hypertension & 1.0 & $0.7-1.4$ & 0.504 & 0.6 & $0.3-0.9$ & 0.015 \\
\hline Diabetes & 1.1 & $0.7-1.5$ & 0.606 & 1.7 & $1.0^{\mathrm{a}}-2.7$ & 0.984 \\
\hline Chronic lung disease & 1.1 & $0.8-1.6$ & 0.691 & 0.9 & $0.5-1.5$ & 0.297 \\
\hline Immunosuppression & NA & NA & NA & 3.8 & $1.6-7.7$ & 0.998 \\
\hline Chronic kidney disease & NA & NA & NA & 2.3 & $1.3-3.9$ & 0.997 \\
\hline \multicolumn{7}{|l|}{ Symptoms at onset of illness ${ }^{d}$} \\
\hline Fever $\left(\geq 38^{\circ} \mathrm{C}\right)$ & 1.4 & $0.9-2.0$ & 0.953 & 1.7 & $1.0-3.0$ & 0.966 \\
\hline Dyspnoea & 2.5 & $1.8-3.4$ & $>0.999$ & 2.1 & $1.2-3.4$ & 0.995 \\
\hline Headache & 0.6 & $0.4-0.9$ & 0.007 & 0.7 & $0.3-1.4$ & 0.158 \\
\hline \multicolumn{7}{|l|}{ Biological findings } \\
\hline Lymphocytes count $<1,000, \operatorname{per} \mu \mathrm{L}^{\mathrm{e}}$ & 1.4 & $1.1-2.0$ & 0.993 & 0.7 & $0.4-1.1$ & 0.080 \\
\hline Neutrophil count $\geq 8,000$, per $\mu L^{f}$ & 2.2 & $1.5-3.0$ & $>0.999$ & 1.9 & $1.0^{\mathrm{a}}-3.0$ & 0.983 \\
\hline CRP $100-199 \mathrm{mg} / \mathrm{L}^{\mathrm{g}}$ & 1.7 & $1.2-2.3$ & $>0.999$ & 2.0 & $1.1-3.2$ & 0.993 \\
\hline $\mathrm{CRP} \geq 200 \mathrm{mg} / \mathrm{L}^{\mathrm{g}}$ & 4.4 & $2.7-6.7$ & $>0.999$ & 1.9 & $0.9-3.5$ & 0.956 \\
\hline$A S T \geq 2 N^{h}$ & 0.9 & $0.7-1.2$ & 0.283 & 1.1 & $0.7-1.6$ & 0.611 \\
\hline
\end{tabular}

AST: aspartate aminotransferase; BMI: body mass index; Crl: credible interval; CRP: C-reactive protein; ICU: intensive care unit; NA: not applicable $(0.025<\operatorname{Pr}($ diff $>0)<0.975$ in the univariate analysis so not included in the multivariate model); $2 \mathrm{~N}$ : twice the upper limit of normal value; OR: odds ratio; Pr: probability.

a These values are $>1$.

${ }^{\mathrm{b}}$ Reference for the comparison is female sex.

' Reference is the absence of the comorbidity.

${ }^{\mathrm{d}}$ Reference is the absence of the symptom.

${ }^{\text {e }}$ Reference is lymphocyte count $\geq 1,000$, per $\mu \mathrm{L}$.

${ }^{f}$ Reference is neutrophil count $<8,000$, per $\mu \mathrm{L}$.

${ }^{g}$ Reference is C-reactive protein $<100 \mathrm{mg} / \mathrm{L}$.

${ }^{\text {h }}$ Reference is $\mathrm{AST}<2 \mathrm{~N}$.

No centre effect was observed, the proportion of subjects fulfilling the primary outcome being similar in both centres. The following variables (hypertension, diabetes and chronic lung disease) were forced into the model for their clinical relevance. Missing data were imputed using prior distributions derived from the observed data. Probabilities near 1 or o are both suggestive of an effect, respectively an OR larger or smaller than 1, and are marked in bold.

7 (receiving invasive mechanical ventilation), and five (0.5\%) patients died (score of 8 ) (Supplementary Figure 1).

\section{Biological and radiological findings}

Among the inflammatory parameters at admission for patients with available data, mean C-reactive protein value was $105 \mathrm{mg} / \mathrm{L}$ (SD: 82) - normal range< 4 , mean neutrophil value was 5,652 per $\mu \mathrm{L}$ (SD:4,329) - normal range:1,800-7,900, and mean lymphocyte value 1,061 per $\mu \mathrm{L}$ (SD:1,407) - normal range:1,0004,000 (Supplementary Table 2). C-reactive protein was $\geq 100 \mathrm{mg} / \mathrm{L}$ in $445(44.7 \%)$ patients and lymphopenia was common $(618,60.9 \%)$. Renal failure, which was considered when creatinine concentration was $\geq 133 \mu \mathrm{mol} / \mathrm{L}$, was found in 147 (14.4\%) patients.
At admission, a chest computed tomography result was classified as compatible with COVID-19 in 616/687 (89.7\%) patients. On day 7, 24 patients had been diagnosed with pulmonary embolism, including 18 patients with severe disease.

\section{Treatment}

During the first 7 days of hospitalisation, 815 (78.0\%) patients received antibiotics: most received beta-lactams $(n=785,75.1 \%)$, over one-third received macrolides $(n=388,37.1 \%)$ and very few received other antibiotics ( $n=13,1.2 \%)$. A total of $437(41.8 \%)$ patients received different antiviral treatments: lopinavir/ritonavir $(n=259,24.8 \%)$, hydroxychloroquine $(n=163$, $15.6 \%)$, oseltamivir $(n=8,0.8 \%)$ and remdesivir $(n=7$, 
$0.7 \%)$. In addition, corticosteroids and anti-interleukin 6 were administered to $38(3.6 \%)$ and $17(1.6 \%)$ patients, respectively.

Oxygen support was required for $802(76.7 \%)$ patients, via a nasal cannula or facial mask for $481(46.0 \%)$, noninvasive mechanical ventilation for $27(2.6 \%)$ and invasive mechanical ventilation for $294(28.1 \%)$ patients. Extracorporeal membrane oxygenation was used in 17 patients (1.6\%) and $224(21.4 \%)$ patients required vasopressors.

\section{Clinical outcome}

The primary composite end-point event on day 7 occurred in 424 (40.6\%) patients, including $335(32.1 \%)$ who were admitted to the ICU for ARDS, and 115 (11.0\%) who died, among them 26 patients died in the ICU. The mean time from admission to ICU transfer was 1 day (SD: 2). On day 7, 155 (14.8\%) patients fully recovered and were discharged, while $24(2.3 \%)$ patients were discharged from ICU but remained hospitalised. In-hospital mortality on day 30 was $18.7 \%(n=195)$.

Survival analysis showed lower event-free survival (i.e. with no admission to ICU or death) in patients older than $\geq 65$ years $(\operatorname{Pr}($ hazard ratio $(H R)>1)>0.99)$ and in patients with a $B M I \geq 25 \mathrm{~kg} / \mathrm{m}^{2}(\operatorname{Pr}(H R>1)>0.99$; Figure 2). Moreover, age and BMI were inversely correlated in patients with severe disease $(r=-0.25)$ and death $(r=-0.26)$ on day7 (Figure 2). Survival was lower in patients with an eight-category ordinal scale of 5 and 7 at admission compared with those with a score of 4 $(\operatorname{Pr}(H R>1)>0.99$ for each comparison; Supplementary Figure 1).

\section{Factors associated with severe disease and} death in multivariate analysis

Using multivariate analysis (Table 2), we found that advanced age (OR:1.1 per10-year increase; $95 \% \mathrm{Crl}: 1.0-$ 1.2), being male (OR:2.1;95\% Crl:1.5-2.8), being overweight (OR:1.8;95\% Crl:1.2-2.7), and obesity (OR:2.2; 95\% Crl:1.5-3.3) were related to severe COVID-19.

Presenting with dyspnoea at admission (OR: $2.5 ; 95 \%$ Crl: $1.8-3.4$ ) was related to an increased risk of severe disease whereas presenting with a headache (OR: $0.6 ; 95 \% \mathrm{Crl}: 0.4-0.9$ ) was related to a decreased risk of developing severe COVID-19.

Inflammatory parameters at admission, including a C-reactive protein level of $100-200 \mathrm{mg} / \mathrm{L}$ (OR: $1.7 ; 95 \%$ Crl: $1.2-2.3$ ) and $\geq 200 \mathrm{mg} / \mathrm{L}$ (OR: $4.4 ; 95 \% \mathrm{Crl}: 2.7-6.7$ ), neutrophil count $\geq 8,000$ per $\mu \mathrm{L}$ (OR:2.2; 95\%Crl:1.5-3.0), and lymphocyte count $<1,000$ per $\mu \mathrm{L}$ (OR:1.4; 95\% Crl:1.1-2.0) were associated with the development of severe disease.

Factors associated with death were advanced age (OR: 2.7, per10-year increase; 95\% Crl:2.1-3.4), being male (OR: 1.7;95\% Crl:1.1-2.7), immunosuppression (OR:3.8;95\%Crl:1.6-7.7), diabetes(OR:1.7;95\%Crl:1.0-2.7), chronic kidney disease (OR: 2.3; 95\% Crl: 1.3-3.9), dyspnoea (OR: $2.1 ; 95 \% \mathrm{Crl}: 1.2-3.4)$ and inflammatory parameters such as a C-reactive protein level of 100$199 \mathrm{mg} / \mathrm{L}$ (OR:2.0;95\% Crl:1.1-3.2) and neutrophil count $\geq 8$, 00o per $\mu \mathrm{L}$ (OR:1.9; 95\% Crl:1.0-3.0).

\section{Discussion}

We describe a large cohort of hospitalised patients with confirmed SARS-CoV-2 infection during the first pandemic wave in France. Using multivariate analysis, we found that, advanced age, being male, inflammation parameters and dyspnoea were associated with the development of severe disease and death. Being overweight or obese was associated with severe disease only, whereas comorbidities such as chronic kidney disease, diabetes and immunosuppression increased the risk of death.

The high prevalence of overweightedness and obesity in this European cohort and their identification as risk factors for severe disease is of major interest. These findings were not described from the early pandemic in Chinese studies. Almost 75\% (661/897) of our patients with information on $\mathrm{BMI}$ had a $\mathrm{BMI} \geq 25 \mathrm{~kg} / \mathrm{m}^{2}$. This proportion appears higher than in French and European populations that have reported prevalences of $45 \%$ and $53 \%$ in 2014 , respectively [14]. Interestingly, obesity was described as an important risk factor for severe disease during the 2009 influenza $A\left(\mathrm{H}_{1} \mathrm{~N}_{1}\right)$ pandemic [15]. Simonnet et al. have reported that obesity is associated with the need for invasive mechanical ventilation in COVID-19 patients [16]. Moreover, in our severely ill patients, age and BMI were inversely correlated, suggesting that $\mathrm{BMI}$ is an important risk factor for younger people, as previously reported by Kass et al. [17]. Similarly, obesity has been identified as a risk factor for hospital and ICU admission in COVID-19 patients younger than 60 years in the United States (US) [18]. The potential contribution of obesity to COVID-19 severity might originate from ventilation disorders of mechanical origin [19]. Moreover, obesity is associated with impaired immune response and chronic inflammation, resulting in a higher rate of severe infections $[20,21]$.

Interestingly, obesity was not associated with death in our study. This result is consistent with previous studies and might be explained by the younger age of overweight and obese patients compared to other patients with severe disease, where advanced age was an important risk factor for death [22]. Being overweight as a risk factor of severe COVID-19, especially in younger patients, is of critical importance for public health. The prevalence of obesity in Europe and the US is high [13]. Thus, COVID-19 pandemic could be more problematic in western countries than in Asia, further justifying the implementation in such countries of measures to prevent SARS-CoV-2 infection and decrease the incidence of severe COVID-19. 
Among the main factors associated with severe disease and death, increasing age and being male have been reported in most of the cohorts investigated $[5,8,9,23,24]$. Excess all-cause mortality was detected during the COVID-19 pandemic in Europe between March and April 2020, especially among patients aged 65 years and older [25]. The mean age of 66 years found by our study is higher than previously described and might be explained by its focus on a hospitalised population that is likely older than the outpatients included in other studies $[5,12,13,26]$. Most patients had at least one comorbidity (58.7\%), among which hypertension was the most prevalent. Hypertension was associated with a lower risk of death. Sixty per cent of our patients with hypertension were treated with angiotensin-converting enzyme inhibitors or angiotensin II receptor antagonists. Such treatments might have a protective effect, as suggested by Zhang et al. [27]. Other comorbidities, including immunosuppression, diabetes and chronic kidney disease were associated with death in our study, consistent with the literature [22]. We did not, however, find these comorbidities associated with severe disease, possibly because some patients with comorbidities and advanced age might not have been admitted to the ICU, especially at the peak of the epidemic. These findings are of importance for public health and triage. Moreover, immunosuppressed patients should be carefully monitored, and prophylactic measures against infection should be applied in this at-risk population.

Dyspnoea is an important clinical parameter that is associated with severe disease and death, especially since patients with hypoxaemia do not always show signs of respiratory distress [28]. In contrast, headaches were associated with mild illness, possibly because of under-reporting of this symptom in patients with severe respiratory symptoms. Furthermore, extrapulmonary symptoms such as anosmia have been reported as associated with less severe respiratory disease [26].

Severe disease and death are associated with high levels of inflammatory parameters represented by elevated C-reactive protein, neutrophilia and lymphopenia. These abnormalities suggest that SARS-CoV-2 infection may be associated with a 'cytokine storm', an excessive and prolonged cytokine response that could play an important role in disease severity $[8,29]$. Pederson et al. reported that severe of COVID-19 is associated with impairment of T-cells' response and high levels of cytokines, such as interleukin- 6 and tumour necrosis factor alpha [30]. Therefore, identification of subgroups of patients with biological inflammatory profile and the use of targeted anti-inflammatory drugs, such as steroids or anti-interleukin-6, could be of substantial benefit [31].

Despite prospective data collection, our study has limitations. First, possible lack of exhaustive clinical data could limit our findings, as well as self-reporting of comorbidities. Secondly, we did not collect D-dimer and other inflammatory markers, such as interleukin-6 or procalcitonin, that are now reported to be associated with severe disease [9,32]. Interleukin-6 concentration is not evaluated in daily clinical practice, whereas D-dimer might be either associated with the occurrence of thrombosis or with infection. Most of our patients were rapidly treated with anti-thrombotic prophylaxis, and measurement of D-dimer levels was not routinely performed. Further, the endpoint of the study was recorded on day 7 to evaluate rapid worsening. A longer outcome may have increased numbers of patients with severe disease and death. However, the mean time from hospitalisation to ICU transfer was 1 day in our cohort, and the difference in survival analysis mainly occurred within the first week following admission (Figure 2), reinforcing our choice of early outcomes. Finally, treatments specifically introduced for the infectious episode were not considered in the statistical analysis of risk factors present at admission. While our results should be treated with caution considering the limitation of observational studies to infer causality, we gathered data from a large cohort of patients, using appropriate statistical methods involving Bayesian approaches and multivariate analysis. All predictive variables are easily obtainable in clinical practice. We believe that our results are generalisable for other European countries because we have used routine clinical data and the prevalence of obesity is important in many of these countries [13].

\section{Conclusion}

Advanced age, male sex, being overweight or obese (particularly in younger patients), immunosuppression, diabetes, chronic kidney disease, and high inflammation are the main risk factors for severe disease or death in COVID-19. Identifying these risk factors is of tremendous importance to improve the management of patients at risk (triage, specific treatments), as well as to guide the implementation of public health measures aiming to limit the impact of this pandemic on vulnerable populations.

\section{Acknowledgements}

Marion Schaeffer, Emilia Koestel, Laurent Mifsud, Nathalie Pfister, Joffrey Alcazar, Emilie Auffret (CHU de Strasbourg, Department of Ophthalmology); Gabriel Nisand (CHU de Strasbourg, Laboratoire de Biostatistique et d'Informatique Médicale) and Raoul Herbrecht (Department of Haematology, Institut de Cancérologie de Strasbourg) for their contribution to the study. We would like to thank Jean-Marie Danion and Damien Heitz (CHU de Strasbourg, Establishment's Medical Commission), the director board of the CHU de Strasbourg and all the health care workers.

Funding: This study was supported by the Strasbourg University Hospital [COVID-HUS study- HUS ${ }^{\circ} 7760$ ]. 


\section{Conflict of interest}

YH reports personal fees from Pfizer, MSD, and Astellas, outside the submitted work. FD declares personal fees from Gilead, outside the submitted work. Other authors: no reported conflict of interest.

COVID-19 Alsace Study group: MO reports personal fees from Canon Medical Systems Europe, BMS, and Bracco Imaging, outside the submitted work. Other authors: no reported conflict of interest.

\section{Authors' contributions}

CK, YR, YH and FD designed the study and had full access to all of the data. CK, CLH, JM, BD, YR, AH, Y-JZ, VP, RC-J, VG, $\mathrm{LK}, \mathrm{NL}, \mathrm{OH}, \mathrm{FD}$ have collected the data. FG has performed virological analysis. TB and NM have designed and performed the statistical analysis. CK, CLH, TF, YR, NM, YH and FD have interpreted the data. CK and FD wrote the first draft of the manuscript. All authors have critically revised the manuscript and approved the final version.

All authors of the COVID-19 Alsace Study group have collected data and revised the final version.

\section{References}

1. Zhu N, Zhang D, Wang W, Li X, Yang B, Song J, et al. , China Novel Coronavirus Investigating and Research Team. A Novel Coronavirus from Patients with Pneumonia in China, 2019. N Engl J Med. 2020;382(8):727-33. https://doi.org/10.1056/ NEJMoa2001017 PMID: 31978945

2. World Health Organization (WHO). WHO Director-General's opening remarks at the media briefing on COVID-19. Geneva: WHO; 13 March 2020. [Accessed 19 Apr 2020]. Available from: https://www.who.int/dg/speeches/detail/who-directorgeneral-s-opening-remarks-at-the-mission-briefing-on-covid19---13-march-2020

3. European Centre for Disease Prevention and Control (ECDC). COVID-19 situation update for the EU/EEA and the UK, as of 3 August 2020. Stockholm: ECDC; [Accessed 3 Aug 2020]. Available from: https://www.ecdc.europa.eu/en cases-2019-ncov-eueea

4. Huang C, Wang Y, Li X, Ren L, Zhao J, Hu Y, et al. Clinical features of patients infected with 2019 novel coronavirus in Wuhan, China. Lancet. 2020;395(10223):497-506. https://doi. org/10.1016/S0140-6736(20)30183-5 PMID: 31986264

5. Guan W-J, Ni Z-Y, Hu Y, Liang W-H, Ou C-Q, He J-X, et al. China Medical Treatment Expert Group for Covid-19. Clinical Characteristics of Coronavirus Disease 2019 in China. N Engl J Med. 2020;382(18):1708-20. https://doi.org/10.1056/ NEJMoa2002032 PMID: 32109013

6. Bai Y, Yao L, Wei T, Tian F, Jin D-Y, Chen L, et al. Presumed Asymptomatic Carrier Transmission of COVID-19. JAMA. 2020;323(14):1406-7. https://doi.org/10.1001/jama.2020.2565 PMID: 32083643

7. Wilder-Smith A, Chiew CJ, Lee VJ. Can we contain the COVID-19 outbreak with the same measures as for SARS? Lancet Infect Dis. 2020;20(5):e102-7. https://doi.org/10.1016/S14733099(20)30129-8 PMID: 32145768

8. Wu C, Chen X, Cai Y, Xia J, Zhou X, Xu S, et al. Risk Factors Associated With Acute Respiratory Distress Syndrome and Death in Patients With Coronavirus Disease 2019 Pneumonia in Wuhan, China. JAMA Intern Med. 2020;180(7):934-43. https:// doi.org/10.1001/jamainternmed.2020.0994 PMID: 32167524

9. Zhou F, Yu T, Du R, Fan G, Liu Y, Liu Z, et al. Clinical course and risk factors for mortality of adult inpatients with COVID-19 in Wuhan, China: a retrospective cohort study. Lancet. 2020;395(10229):1054-62. https://doi.org/10.1016/S01406736(20)30566-3 PMID: 32171076

10. Peiris JSM, Yuen KY, Osterhaus ADME, Stöhr K. The severe acute respiratory syndrome. N Engl J Med. 2003:349(25):2431 41. https://doi.org/10.1056/NEJMra032498 PMID: 14681510

11. Beigel JH, Tomashek KM, Dodd LE, Mehta AK, Zingman BS, Kalil AC, et al. Remdesivir for the Treatment of Covid-19
- Preliminary Report. N Engl J Med. 2020;NEJMoa2007764. https://doi.org/10.1056/NEJMoa2007764

12. World Health Organization (WHO). Real-time-rt-pcr-assays-forthe-detection-of-sars-cov-2-institut-pasteur-paris. Geneva: WHO. [Accessed 20 Apr 2020]. Available from: https://www. who.int/docs/default-source/coronaviruse/real-time-rt-pcrassays-for-the-detection-of-sars-cov-2-institut-pasteur-paris. pdf?sfvrsn $=3662 \mathrm{fcb} 6 \_2$

13. World Health Organization (WHO). Obesity. Geneva: WHO. [Accessed 24 Jul 2020]. Available from: https://www.who.int/ topics/obesity/en/

14. Marques A, Peralta M, Naia A, Loureiro N, de Matos MG. Prevalence of adult overweight and obesity in 20 European countries, 2014. Eur J Public Health. 2018;28(2):295-300. https://doi.org/10.1093/eurpub/ckx143 PMID: 29036436

15. Louie JK, Acosta M, Winter K, Jean C, Gavali S, Schechter $\mathrm{R}$, et al. , California Pandemic $\left(\mathrm{H}_{1} \mathrm{~N}_{1}\right)$ Working Group. Factors associated with death or hospitalization due to pandemic 2009 influenza $A\left(\mathrm{H}_{1} \mathrm{~N}_{1}\right)$ infection in California. JAMA. 2009;302(17):1896-902. https://doi.org/10.1001/ jama.2009.1583 PMID: 19887665

16. Simonnet A, Chetboun M, Poissy J, Raverdy V, Noulette J, Duhamel A, et al. , LICORN and the Lille COVID-19 and Obesity study group. High prevalence of obesity in severe acute respiratory syndrome coronavirus-2 (SARS-CoV-2) requiring invasive mechanical ventilation. Obesity (Silver Spring). 2020;28(7):1195-9. https://doi.org/10.1002/oby.22831 PMID: 32271993

17. Kass DA, Duggal P, Cingolani O. Obesity could shift severe COVID-19 disease to younger ages. Lancet. 2020;395(10236):1544-5. https://doi.org/10.1016/S01406736(20)31024-2 PMID: 32380044

18. Lighter J, Phillips M, Hochman S, Sterling S, Johnson D, Francois $\mathrm{F}$, et al. Obesity in patients younger than 60 years is a risk factor for Covid-19 hospital admission. Clin Infect Dis. 2020;71(15):896-7. https://doi.org/10.1093/cid/ciaa415 PMID: 32271368

19. Peters U, Suratt BT, Bates JHT, Dixon AE. Beyond BMI: Obesity and Lung Disease. Chest. 2018;153(3):702-9. https://doi. org/10.1016/j.chest.2017.07.010 PMID: 28728934

20. Huttunen R, Syrjänen J. Obesity and the outcome of infection. Lancet Infect Dis. 2010;10(7):442-3. https://doi.org/10.1016/ S1473-3099(10)70103-1 PMID: 20610324

21. Martí A, Marcos A, Martínez JA. Obesity and immune function relationships. Obes Rev. 2001;2(2):131-40. https://doi. org/10.1046/j.1467-789x.2001.00025.x PMID: 12119664

22. Kim L, Garg S, O’Halloran A, Whitaker M, Pham H, Anderson EJ, et al. Risk Factors for Intensive Care Unit Admission and In-hospital Mortality among Hospitalized Adults Identified through the U.S. Coronavirus Disease 2019 (COVID-19) Associated Hospitalization Surveillance Network (COVID-NET) Clin Infect Dis. 2020;ciaa1012. https://doi.org/10.1093/cid/ ciaa1012 PMID: 32674114

23. Grasselli G, Zangrillo A, Zanella A, Antonelli M, Cabrini L, Castelli A, et al. , COVID-19 Lombardy ICU Network. Baseline Characteristics and Outcomes of 1591 Patients Infected With SARS-CoV-2 Admitted to ICUs of the Lombardy Region, Italy. JAMA. 2020;323(16):1574-81. https://doi.org/10.1001/ jama.2020.5394 PMID: 32250385

24. Wang D, Hu B, Hu C, Zhu F, Liu X, Zhang J, et al. Clinical Characteristics of 138 Hospitalized Patients With 2019 Novel Coronavirus-Infected Pneumonia in Wuhan, China. JAMA. 2020;323(11):1061-9. https://doi.org/10.1001/jama.2020.1585 PMID: 32031570

25. Vestergaard LS, Nielsen J, Richter L, Schmid D, Bustos N, Braeye T, et al. , ECDC Public Health Emergency Team for COVID-19. Excess all-cause mortality during the COVID-19 pandemic in Europe - preliminary pooled estimates from the EuroMOMO network, March to April 2020. Euro Surveill. 2020;25(26):2001214. https://doi.org/10.2807/1560-7917. ES.2020.25.26.2001214 PMID: 32643601

26. Yan CH, Faraji F, Prajapati DP, Ostrander BT, DeConde AS. Self-reported olfactory loss associates with outpatient clinical course in COVID-19. Int Forum Allergy Rhinol. 2020;10(7):82131. https://doi.org/10.1002/alr.22592 PMID: 32329222

27. Zhang P, Zhu L, Cai J, Lei F, Qin J-J, Xie J, et al. Association of Inpatient Use of Angiotensin-Converting Enzyme Inhibitors and Angiotensin II Receptor Blockers With Mortality Among Patients With Hypertension Hospitalized With COVID-19. Circ Res. 2020;126(12):1671-81. https://doi.org/10.1161/ CIRCRESAHA.120.317134 PMID: 32302265

28. Bertran Recasens B, Martinez-Llorens JM, Rodriguez-Sevilla JJ, Rubio MA. Lack of dyspnea in patients with Covid-19: another neurological conundrum? Eur J Neurol. 2020;ene.14265. https://doi.org/10.1111/ene.14265 PMID: 32301553 
29. Channappanavar R, Perlman S. Pathogenic human coronavirus infections: causes and consequences of cytokine storm and immunopathology. Semin Immunopathol. 2017;39(5):529-39. https://doi.org/10.1007/s00281-017-0629-x PMID: 28466096

30. Pedersen SF, Ho Y-C. SARS-CoV-2: a storm is raging. J Clin Invest. 2020;130(5):2202-5. https://doi.org/10.1172/JCl137647 PMID: 32217834

31. Horby P, Lim WS, Emberson JR, Mafham M, Bell JL, Linsell L, et al. , RECOVERY Collaborative Group. Dexamethasone in Hospitalized Patients with Covid-19 - Preliminary Report. N Engl J Med. 2020:NEJMoa2021436. PMID: 32678530

32. Cummings MJ, Baldwin MR, Abrams D, Jacobson SD, Meyer BJ, Balough EM, et al. Epidemiology, clinical course, and outcomes of critically ill adults with COVID-19 in New York City: a prospective cohort study. Lancet. 2020;395(10239):176370. https://doi.org/10.1016/S0140-6736(20)31189-2 PMID: 32442528

\section{License, supplementary material and copyright}

This is an open-access article distributed under the terms of the Creative Commons Attribution (CC BY 4.0) Licence. You may share and adapt the material, but must give appropriate credit to the source, provide a link to the licence and indicate if changes were made.

Any supplementary material referenced in the article can be found in the online version.

This article is copyright of the authors or their affiliated institutions, 2020. 